\title{
THE EFFECT OF PSYCHOLOGICAL AND ENVIRONMENTAL FACTORS ON ACADEMIC PERFORMANCE OF VIDEO GAMERS
}

\author{
Kirill M. Yurov, Middle Georgia State College, kirill.yurov@mga.edu \\ YuliyaV. Yurova, Nova Southeastern University,yy21@nova.edu \\ Myungjae Kwak, Middle Georgia State College, myungjae.kwak@mga.edu \\ Chih-Hao (Justin) Ku, Lawrence Technological University,ku.justin@gmail.com
}

\begin{abstract}
This study presents an initial attempt to uncover psychological and environmental factors influencing the academic performance of video gamers. We surveyed IT undergraduate students with respect to their video-gaming experiences. For the psychological factors at hand, we found that task awareness or the ability to stay focused on business activities has the potential to influence positively academic performance. Among the environmental factors, platform diversity or ability to operate multiple platforms and game genres appeared to have the effect on academic performance. Versatility in operating game platforms leads to advanced cognitive and technical skills that in turn could boost student grades. As for game genres, we found that certain game genres such as sports games are more likely to result in poorer performance. The results of this investigation would help us design future studies focusing on developing instructional game applications.
\end{abstract}

Keywords: Video Games, Gaming Behavior, Video-gaming Technology, Academic Performance

\section{INTRODUCTION}

Video games have become a popular means of entertainment of adult population, including college students. The latter are engaged in the formal learning process that requires the investment of a considerable amount of time and effort in achieving good performance. It could be argued that time spent playing video games could have been invested in the pursuit of better grades. At the same time, there is evidence that video games could foster intellectual development $[2,3,14]$. Also, certain behavioral dispositions such as self-control and task awareness can potentially regulate the degree of immersion in video games [11,15].

The importance of studying video-gaming technology in educational settings has been long emphasized in the literature due to potential benefits $[10,1,16,5]$. Deploying video-gaming tools (also called instructional games) in the context of learning realizes benefits both in the area of personal psychology and knowledge acquisition. Thus, Sitzmann [13] conducted a mega-study aggregating the findings of research focusing on video-gaming tools. The study established that those individuals who utilized instructional games reported a $20 \%$ higher level of self-efficacy compared to a control group. Learners also delivered higher results in terms of declarative knowledge (11\%) and procedural knowledge (14\%). While this study does not directly focus on the use of computer-based gaming technology for learning purposes, its findings could provide insights relevant for designing instructional games potentially attractive for learners.

\section{LITERATURE REVIEW AND MODEL DEVELOPMENT}

The appeal of video-gaming technology for student audiences has been well documented in the literature [9,8]. Under certain circumstances, the use of this technology leads to poorer academic outcomes. Players who focus on purely entertainment-oriented games such as shooting are more likely to cause their academic performance to suffer as a result [15]. On contrary, gamers who play strategy, puzzle, simulation games are more likely to immerse themselves in the environment which enhances their creativity and intellectual growth, the conditions which stimulate academic progress [15]. In addition, academic performance could be affected by such factors as task awareness, self-control, socialization, playing frequency and platform diversity. Therefore, it is important to study factors, both behavioral and environmental, affecting academic performance of learners. We will proceed to defining these factors as well as explaining how they affect the learning progress of college population.

Task awareness is understood in this study as the ability to balance the amount of time invested in activities primarily associated with leisure such as playing video-games and the amount of time and effort required to fulfill 
obligations related to work and study. In a similar vein, Goel, Johnson, Junglas \& Ives [6] attributed to the effect of task awareness, on the part of users of computer simulations labeled Virtual Worlds, to stay continuously engaged in related activities. A similar concept, Conscientiousness, is attributed by Ventura, Shute \& Kim [15] to gamers' ability to regulate their time commitment toward playing video games.

Self-control is defined as the ability to stay on the course with respect to making a conscientious effort on the part of video gamers to not to lose control over temptations such as the pursuit of leisure and escape from reality. A number of studies revealed that a lack of self-control tends to bring about addictive behavior of the part of gamers $[11,12]$. Flow defined as losing a sense of time due to excessive video-gaming could be one of the negative outcomes resulting from the loss of self-control $[11,12]$.

Socialization refers to the tendency to engage in face-to-face communications versus using virtual means for maintaining social connections. Research has addressed the influence of social media on academic performance and self-regulation [4, 7]. We predict that face-to-face socialization would have a positive impact of academic scores for video-game players. Similar to prior research [9], we expect that playing frequency would affect academic performance negatively as more time is spend on playing video games. Platform diversity stands for the skill required to operate multiple gaming platforms or environments. There are various platforms at the disposal of players. In this study, we address such platforms as a personal computer, console, arcade and mobile. We predict that platform diversity would affect the acquired level of knowledge measured by academic performance favorably as the diversified technology base points to advanced computer literacy on the part of gamers. The resultant model which contains both psychological and environmental factors affecting academic performance is depicted in Figure 1 .

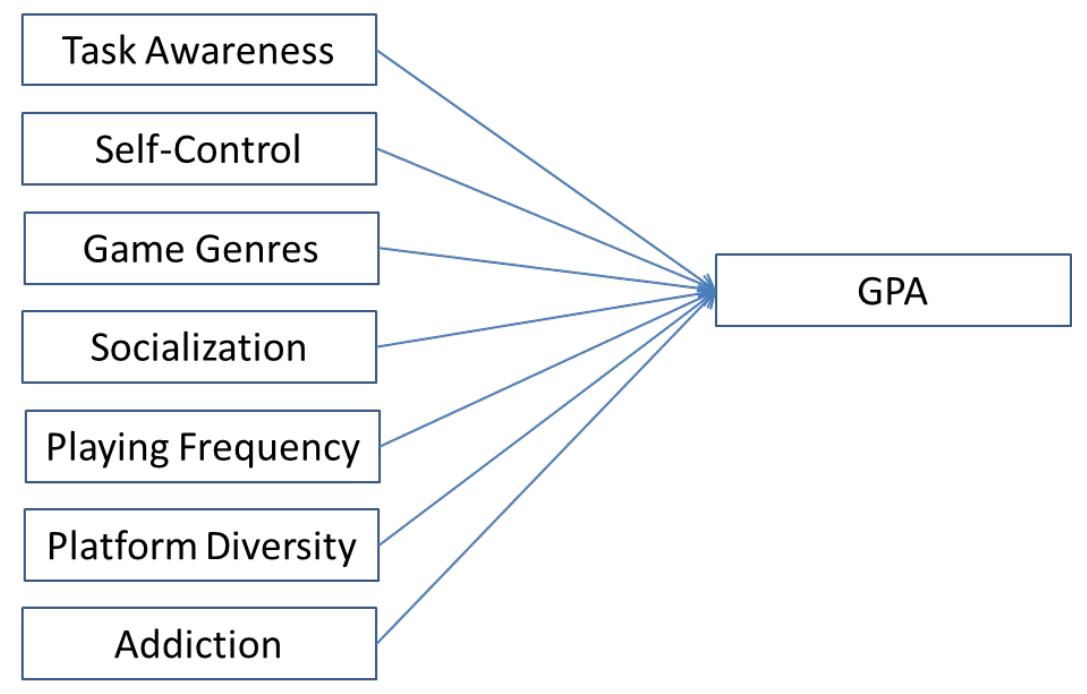

Figure 1. Constructs and research model

\section{Research Question}

To obtain insights for designing and developing instructional gaming software for K-12 and college students, we reviewed literature focusing on gaming behavior and academic performance, and came up with several research variables and devised the following research question:

Are a set of variables such as task awareness, self-control, game genres, socialization, playing frequency, platform diversity, addiction associated with college students' academic performance? If so, how are they related, positively or negatively?

\section{RESEARCH METHODOLOGY}


We deployed multiple regression to analyze the effects of task awareness, self-control, socialization, playing frequency, platform diversity, addiction and game genres on the GPA, the academic performance variable. Demographic questions about age, gender, preferred mode of learning (online vs. traditional in class), full-time student status as well as employment status were also included in the analytical model. The values for the dependent variable in this study, GPA, were secured via the grade-reporting system.

\section{Data}

The data for this study was collected by 3 instructors who taught 13 undergraduate IT classes in the Fall 2013 semester at a four-year college in the Southeastern United States. Seven out of 13 classes were taught via online means. The overall student body for 13 classes comprised of 221 students who received a link to the online survey developed by the authors. The survey included 30 questions overall organized in 4 categories: gaming experience, social and academic experience, personal information and open-ended questions. In return for participation, students were given bonus points. Those students who did not wish to take part in the survey were offered an alternative project to complete. The values for student GPAs were taken from the college's enrollment system. Given the sensitive nature of this research, the resultant dataset did not contain student names which were replaced by numeric codes.

A total of 117 usable surveys were completed and consequently provided the quantitative foundation for this study. The academic performance of survey respondents using a 4.0 scale GPA ranged from 1.82 to 4.0 with the average of 3.03. The survey respondents were predominantly male (about $78 \%$ ), full-time students $(81.20 \%)$ with a part or full time job $(65 \%)$. The sample was about evenly divided between younger (24 years old or less) and older (25 years old or more) students. Tables 1 and 2 present the descriptive statistics and correlations for the variables in the study.

Table 1. Descriptive statistics of variables in the study $(n=117)$

\begin{tabular}{l|rrrr}
\hline & Mean & $\begin{array}{c}\text { Standard } \\
\text { Deviation }\end{array}$ & Min & Max \\
\hline GPA & 3.03 & 0.50 & 1.83 & 4.00 \\
$\begin{array}{l}\text { Frequent Playing } \\
\text { (proportion of players playing more than 7 times per week) }\end{array}$ & $29.06 \%$ & 0.46 & 0 & 1 \\
$\begin{array}{l}\text { Number of Game Platforms } \\
\text { (proportion of players playing 4 platforms or more) }\end{array}$ & $11.11 \%$ & 0.32 & 0 & 1 \\
$\begin{array}{l}\text { Sports Game Players } \\
\text { (most frequently play sports games) }\end{array}$ & $10.26 \%$ & 0.30 & 0 & 1 \\
$\begin{array}{l}\text { Low Task Awareness } \\
\text { (missed an exam or a class because of playing video games) }\end{array}$ & $18.80 \%$ & 0.39 & 0 & 1 \\
$\begin{array}{l}\text { Low Self-control } \\
\text { (forgot things, meal or time while playing video games) }\end{array}$ & $73.50 \%$ & 0.44 & 0 & 1 \\
$\begin{array}{l}\text { High Socialization } \\
\text { (meet with friends more than 2 times a week) }\end{array}$ & $35.90 \%$ & 0.48 & 0 & 1 \\
$\begin{array}{l}\text { Addiction } \\
\text { (played during a class and/ or class breaks) }\end{array}$ & $47.86 \%$ & 0.50 & 0 & 1 \\
$\begin{array}{l}\text { Online Learners } \\
\text { (students who have taken at least 80\% of classes online) }\end{array}$ & $31.62 \%$ & 0.47 & 0 & 1 \\
Gender (proportion of males) & $77.78 \%$ & 0.42 & 0 & 1 \\
Full Time Students (proportion of full time students) & $81.20 \%$ & 0.39 & 0 & 1 \\
$\begin{array}{l}\text { No Job (students without a full- or part-time job) } \\
\text { Age (proportion of students aged 25 years or more) }\end{array}$ & $35.04 \%$ & 0.48 & 0 & 1 \\
\hline & $53.85 \%$ & 0.50 & 0 & 1 \\
\hline
\end{tabular}


Table 2. Correlations of variables in the study $(n=117)$

\begin{tabular}{|c|c|c|c|c|c|c|c|c|c|c|c|c|c|}
\hline & GPA & Freq & NPI & Sports & TAw & SC & Soc & Add & Online & Gen & FT & Job & Age \\
\hline GPA & 1 & & & & & & & & & & & & \\
\hline $\begin{array}{l}\text { Frequent Players } \\
\text { Number of } \\
\text { Platforms }\end{array}$ & -.04 & .25 & 1 & & & & & & & & & & \\
\hline $\begin{array}{l}\text { Sports Game } \\
\text { Low Task }\end{array}$ & -.16 & -.09 & -.03 & 1 & & & & & & & & & \\
\hline Awareness & -.14 & .27 & .18 & -.09 & 1 & & & & & & & & \\
\hline Low Self-control & -.16 & .30 & .09 & -.05 & .29 & 1 & & & & & & & \\
\hline High Socialization & .04 & .23 & .08 & -.14 & -.04 & .01 & 1 & & & & & & \\
\hline Addiction & .05 & .33 & .26 & -.15 & .33 & $\begin{array}{r}.30 \\
-\end{array}$ & .10 & 1 & & & & & \\
\hline Online Learners & .06 & -.03 & .05 & .07 & -.28 & .13 & -.01 & -.21 & 1 & & & & \\
\hline Gender & -.02 & .16 & .12 & .11 & -.01 & .10 & .14 & .18 & -.08 & 1 & & & \\
\hline Fulltime Student & .03 & .12 & .03 & -.20 & .18 & .01 & .18 & .37 & -.19 & -.05 & 1 & & \\
\hline No Job & .04 & -.04 & -.03 & -.13 & .06 & $\begin{array}{r}.08 \\
-\end{array}$ & -.03 & .16 & -.04 & -.21 & $\begin{array}{r}.22 \\
-\end{array}$ & 1 & 1 \\
\hline Age & -.02 & -.12 & .00 & -.03 & -.30 & .05 & -.16 & -.28 & .41 & -.04 & .27 & .03 & \\
\hline
\end{tabular}

\section{RESULTS}

In this study, we analyze the effects of psychological factors such as self-control and task awareness as well as environmental factors such as technology on academic performance. The results of this analysis are displayed in Table 3. As for psychological factors, self-control did not have any effect on the dependent variable. Khang, Kim \& Kim [11] measured the effect of self-control on addiction with respect to playing video games and the relationship was established. Perhaps, our model needs to be re-adjusted in terms of measuring the influence of self-control on addition or playing frequency rather than on the effect of self-controlling behavior on student performance. Task awareness, on the other hand, demonstrated a positive influence on student performance. Students who tend not to miss the deadlines for assignments or classes scored higher on performance. Finally, addiction showed no effect on academic performance. Perhaps, our model needs to be re-adjusted in terms of measuring the influence of playing frequency on addiction rather measuring the effect of addiction on student performance.

Next, we proceed to interpretation of the effect of environmental factors such as technology and knowledge acquisition. When it comes to the effect of playing frequency on the GPA, this factor revealed no effect on student performance. Similarly, the degree of playing analytical video-games such as strategy and puzzle revealed no effect on student performance. Yet, the engagement in playing sports games displayed a negative effect on the GPA which is consistent with the literature. Thus, Ventura, et al. [15] established that gamers who play purely entertainmentoriented games tend to exhibit poorer academic performance. Finally, platform diversity showed a strong positive effect on GPA. This could be explained by the following: students who use multiple video-gaming devices such as a personal computer, console, arcade, mobile tend to have developed cognitive and technical abilities. In accordance with our expectations, familiarity with different platforms appeared to demonstrate that advanced computer literacy tends to affect academic performance favorably. The amount of socialization also showed no effect on the GPA. Perhaps, our model needs to be re-adjusted in terms of measuring the influence of socialization on psychological factors such as self-control and task awareness rather than measuring the effect of socialization on student performance.

Control variables included in this study were age, gender, enrollment status (full-time, part-time), employment status, learning mode (online, face-to-face and hybrid). Control variables employed in this study displayed no effect on student performance. 
Table 3. Academic performance regression model estimates $(n=117)$

\begin{tabular}{l|ll}
\hline Variables & Coefficient & $\begin{array}{l}\text { Standard } \\
\text { Error }\end{array}$ \\
\hline Frequency of playing & -0.063 & 0.114 \\
Number of game platforms & $0.464^{* * *}$ & 0.153 \\
Sports game players & $-0.294^{*}$ & 0.156 \\
Low task awareness & $-0.240^{*}$ & 0.134 \\
Low self-control & -0.155 & 0.113 \\
High socialization & -0.014 & 0.101 \\
Addiction & 0.051 & 0.113 \\
Online learners & 0.039 & 0.110 \\
Gender & -0.024 & 0.117 \\
Fulltime students & -0.021 & 0.132 \\
No Job & 0.042 & 0.100 \\
Age & -0.102 & 0.107 \\
Intercept & & \\
$\mathrm{R}^{2}$ & 3.233 & 0.184 \\
\end{tabular}

$* p$-value $<.10$ and $* * * p$-value $<.01$ for a two-tailed test.

\section{CONCLUSIONS AND FUTURE RESEARCH}

This study presents an initial attempt to ascertain the effect of a set of psychological and environmental factors on the academic performance of video gamers. Among the psychological factors studied, we found that task awareness positively affected academic performance while self-control and addiction had no statistically significant effect on academic performance. Task awareness is clearly a factor that could strongly influence academic performance. It emphasizes the timeliness of student actions. It is more likely that those students who complete assignments on time and attend classes regularly would demonstrate superior academic performance.

Environmental factors focused primarily on the use of technology. We found that platform diversity and game genres influenced the GPA of video gamers. We interpreted that the effect of platform diversity on academic performance is linked to advanced cognitive and technical abilities. Video gamers who rely on diverse computing platforms such as a personal computer, console, arcade and mobile for playing tend to possess more technical knowledge which can potentially help improve their academic performance. Game genres tend to influence academic performance as well. Our analysis revealed that academic performance suffers when gamers are engaged in playing sports games. Other environmental factors such as frequency of playing and socialization appeared to have no influence on academic performance.

Video-gaming technology is making inroads into the learning process at various levels of instruction, including K12 , college and university systems. A fast-evolving, technology-driven modern society increasingly needs welltrained science, technology, engineering and mathematics (STEM) college graduates equipped with innovative problem-solving and higher order thinking skills. It is believed that they can be trained by learning the adequate level of scientific knowledge such as facts, concepts, rules and procedures corresponding to appropriate learning stages. Our future research will focus on designing and developing game-based educational software or interactive learning tools that would help educators deliver STEM curriculum. Such curriculum requires a strong base in the factual knowledge such as facts, jargon, and terminology as well as related conceptual knowledge. Instructional 
game applications are capable of providing the appropriate content at diverse levels of learning under guidance of STEM educators.

\section{REFERENCES}

1. Cataloglu E. (2006). Open source software in teaching physics: A case study on vector algebra and visual representations. The Turkish Online Journal of Educational Technology, 5, 68-74.

2. Choi, B., Huang, J., Jeffrey, A., \& Baek, Y. (2013). Development of a scale for fantasy state in digital games. Computers in Human Behavior, 29(5), 1980-1986.

3. Corpus, J. H., McClintic-Gilbert, M. S., \& Hayenga, A. O. (2009). Within-year changes in children's intrinsic and extrinsic motivational orientations: contextual predictors and academic outcomes. Contemporary Educational Psychology, 34, 154-166.

4. Creighton, J. L., Foster, J. W., Klingsmith, L., and Withey, D. K. (2013). I just look it up: Undergraduate student perception of social media use in their academic success. The Journal of Social Media in Society, 2(2), 26-46.

5. Furió, D., González-Gancedo, S., Juan, M. C., Seguí, I., \& Rando, N. (2013). evaluation of learning outcomes using an educational Iphone game vs. traditional game. Computers \& Education, 64, 1-23.

6. Goel, L., Johnson, N.A., Junglas, I., \& Ives, B. (2011). From space to place: Predicting users' intentions to return to virtual worlds. MIS Quarterly, 35(3), 749-771.

7. Haagsma, M. C., Caplan, S. E., Peters, O., and Pieterse, M. E. (2013). A cognitive-behavioral model of problematic online gaming in adolescents aged 12-22 years. Computers in Human Behavior, 29(1), 202-209.

8. Hellström, C., Nilsson, K. W., Leppert, J., and Åslund, C. (2012). Influences of motives to play and time spent gaming on the negative consequences of adolescent online computer gaming, Computers in Human Behavior, 28(4), 1379-1387.

9. Ip, B., Jacobs, G., and Watkins, A. 2008. Gaming frequency and academic performance. Australasian Journal of Educational Technology, 24(4), 355-373.

10. Kapp, K.M. (2012). The Gamification of learning and instruction: Game-based methods and strategies for training and education. San Francisco, CA: Pfeiffer.

11. Khang, H., Kim, J. K., and Kim, Y. (2013). Self-traits and motivations as antecedents of digital media flow and addiction: The Internet, mobile phones, and video games. Computers in Human Behavior, 29(6), 2416-2424.

12. Lee, C., Aiken, K. D., \& Hung, H. C. (2012). Effects of college students' video-gaming behavior on selfconcept clarity and flow. Social Behavior and Personality, 40(4), 673-680.

13. Sitzmann, T. (2011). A meta-analytic examination of the instructional effectiveness of computer-based simulation games. Personnel Psychology, 64(2), 489-528.

14. Van Eck, R. (2006). Digital game-based learning: It's not just the digital natives who are restless. EDUCAUSE Review,41(2), 16-30.

15. Ventura, M., Shute, V., \& Kim, Y. J. (2012). Video gameplay, personality and academic performance. Computers \& Education, 58(4), 1260-1266.

16. Yurov, K.M., Beasley S.W., Kwak M., and Floyd, K.S. (2014). An initial study of educational game applications supporting the STEM education in K-12 systems. Online Journal of Applied Knowledge Management, 2(1), 169-179. 